\title{
Synthesis and Characterization of Jeffamines with 2-Benzoxa(thia)zolon-3-yl-Acetamido End-Groups
}

\author{
Zoia Mincheva, ${ }^{\dagger}$ Veneta Kalcheva, and Illya Rashkov* \\ Department of Chemistry, University of Sofia, 1 James Bourchier Avenue, \\ 1164 Sofia, Bulgaria \\ *Institute of Polymers, Bulgarian Academy of Sciences, 1113 Sofia, Bulgaria \\ (Received January 21, 1998)
}

KEY WORDS $\quad \alpha, \omega$-Diaminopolyethers / Jeffamines / Degree of $N$-Acylation / 2-Benzoxa(thia)zolone Derivatives / Functional Polymers / Terminal Group /

Water-soluble polymers have been reported as carriers of groups with biocidal or plant growth stimulating activity, ${ }^{1}$ aiming at the reduction in the volatility and toxicity of the bioactive compounds, the improvement of their adhesion or prolongation of their action. Poly(ethylene oxide) (PEO) with end groups of different nature is widely studied in biochemistry and molecular biology, and is commercially used in pharmacological products, cosmetics and food. ${ }^{2,3}$

Benzoxazolone (BO) and its derivatives are objects of numerous studies on the possibilities of their application as drugs and pesticides. ${ }^{4}$ (2-Benzoxazolon-3-yl)acetic acid (BOAA) shows an analgesic activity. ${ }^{5}$ The herbicidal or plant growth regulating activity of benzothiazolon (BT) and (2-benzothiazolon-3-yl)acetic acid (BTAA), are well known. ${ }^{6,7}$ Previously we reported on the synthesis of di-, tri-, and poly(ethyleneglycol) esters of BOAA by the dicyclohexylcarbodiimide (DCC) method. ${ }^{8}$ We found that the conjugates of BOAA with Poly(ethyleneglycol)400 were very useful as substrates of the biocatalyst Penicillin amidase in the preparative synthesis of cephem antibiotics. $^{8,9}$

The extended spectrum of biological activity of benzoxa(thia)zolone derivatives stimulated us to study the synthesis of new polyethers with 2-benzoxa(thia)zolon3 -yl-acetamido end groups by modification of commercial $\alpha, \omega$-diaminopolyethers (Jeffamine ED and D) (Scheme 1). The structural (IR, UV and ${ }^{1} \mathrm{H}$ NMR) and molecular weight characteristics are reported.

\section{EXPERIMENTAL}

\section{Materials}

$O, O^{\prime}$-Bis(2-aminopropyl)polyethylene glycol of molecular weight of $600,900,2000 \mathrm{Da}$ (Jeffamine ED-600, Jeffamine ED-900, and Jeffamine ED-2001), and $O, O^{\prime}-$ bis(2-aminopropyl)polypropylene glycol of molecular weight of 230 and $400 \mathrm{Da}$ (Jeffamine D230 and Jeffamine D400) were commercial products (from Fluka). DCC was Janssen product. BOAA and BTAA were synthesized according to a literature procedure. ${ }^{10}$ All reactions were carried out under dry argon atmosphere.

† To whom correspondence should be addressed.

\section{Measurements}

Size exclusion chromatography (SEC) analyses were performed on a Waters 244 apparatus equipped with a set of Ultrastyragel columns of pore sizes $100,100,500$, and $1000 \AA$, in tetrahydrofuran (THF) at $45^{\circ} \mathrm{C}$, flow rate $1 \mathrm{ml} \mathrm{min}^{-1}$, using double detection (differential refractometer and $\mathrm{UV}-\lambda_{\max } 254 \mathrm{~nm}$ ) and PEO standards for calibration. $\bar{M}_{n}$ of the starting Jeffamines was determined by the method of Vapor pressure osmometry (VPO) on a Knauer apparatus, Germany, in $\mathrm{CHCl}_{3}$ at $45^{\circ} \mathrm{C}$ against benzil as standard.

${ }^{1} \mathrm{H}$ NMR spectra were recorded on a Bruker WM-250 spectrometer $\left(250,13 \mathrm{MHz}\right.$ for $\left.{ }^{1} \mathrm{H}\right)$ at $297 \mathrm{~K}$ in dimethyl sulfoxide (DMSO)- $d_{6}$ with tetramethylsilane (TMS) as internal reference. The IR spectra were taken on a Specord 71R (Zeiss, Oberkochen, Germany) spectrophotometer in $\mathrm{CHCl}_{3}$ and capillary film. The UV spectra were recorded on UV-Vis Perkin-Elmer Lambda 17 spectrophotometer in the range from 200 to $300 \mathrm{~nm}$. The total amount of terminal (2-benzoxa(thia)zolon-3yl)acetamido groups was determined from the UV spectra, using a calibration with BOAA (BTAA) in ethanol (wavelength of maximum absorption $\left(\lambda_{\max }=271\right.$ (278) $\mathrm{nm}$ ).

Preparation of $O, O^{\prime}$-Bis(((2-benzoxazolon-3-yl)-2-acetamido)propyl)polyoxyethylenes (Jeff-BO), (A General Procedure)

Jeff-BO were prepared by reacting Jeffamines of
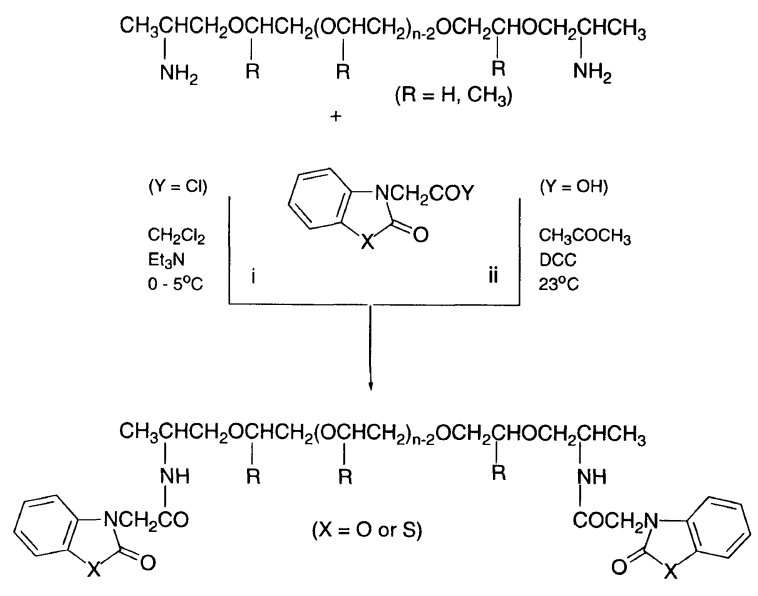

Scheme 1. 
molecular weights from $230 \mathrm{Da}$ to $2000 \mathrm{Da}$ with the chloride of BOAA in dry acetone. The starting Jeffamine $(5 \mathrm{mmol})$ were dissolved in dry $\mathrm{CH}_{2} \mathrm{Cl}_{2}(30-60 \mathrm{ml})$ and $1.5 \mathrm{ml}(11 \mathrm{mmol}) \mathrm{Et}_{3} \mathrm{~N}$ were added. After cooling to $0-5^{\circ} \mathrm{C} 2.3 \mathrm{~g}(11 \mathrm{mmol})$ acid chloride of BOAA (dissolved in dry acetone) were added portionwise to the solution of the corresponding Jeffamine. The reaction mixture was stirred for $1 \mathrm{~h}$ at room temperature for the completion of the acylation (TLC control). The white precipitate of $\mathrm{Et}_{3} \mathrm{~N} \cdot \mathrm{HCl}$ was filtered off and the filtrate was evaporated to dryness. The residue was taken up with cooled acetone and then filtered. The acetone filtrate was precipitated in diethyl ether at $10^{\circ} \mathrm{C}$. The products prepared were purified by repeated precipitation in ether. Typical spectral data (Example, $\operatorname{Jeff}_{400}(\mathrm{BO})$ ): IR $\left(\mathrm{CHCl}_{3}, \mathrm{~cm}^{-1}\right): 3300\left(v_{\mathrm{NH}}\right.$, amide $), 1775\left(v_{\mathrm{CO}}, \mathrm{BO}\right), 1680$ ( $v_{\mathrm{CO}}$, amide), $1100\left(v^{\mathrm{as}}, \mathrm{CH}_{2} \mathrm{OCH}_{2}\right) .{ }^{1} \mathrm{H}$ NMR (DMSO$\left.d_{6}\right), \delta: 1.06-1.24\left(\mathrm{~m}, \mathrm{CH}_{3}\right), 2.93\left(\mathrm{q}, J=7.26 \mathrm{~Hz}, \mathrm{CH}_{3}-\right.$ $\mathrm{CH}(\mathrm{NH})), 3.32-3.51$ (broad $\left.\mathrm{m},\left[\mathrm{OCH}\left(\mathrm{CH}_{3}\right) \mathrm{CH}_{2}\right]_{n}\right)$, $4.45\left(\mathrm{~s}, \mathrm{~N}-\mathrm{CH}_{2}\right), 7.05-7.36(\mathrm{~m}$, arom. $\mathrm{H}), 8.23(\mathrm{~d}$, $J=7.06 \mathrm{~Hz}, \mathrm{NH})$

Preparation of $O, O^{\prime}$-Bis( ((2-benzothiazolon-3-yl)-2-acetamido)propyl)polyoxyethylenes (Jeff-BT), (A General Procedure)

Jeff-BT were prepared by reacting Jeffamines of molecular weights from $400 \mathrm{Da}$ to $2000 \mathrm{Da}$ with BTAA in dry acetone in the presence of DCC. BTAA $(11 \mathrm{mmol})$ was dissolved in acetone $(30-100 \mathrm{ml})$ and a solution of the corresponding Jeffamine $(5 \mathrm{mmol})$ in $10 \mathrm{ml}$ acetone was added. After complete dissolution at room temperature, DCC $(13 \mathrm{mmol})$ in dry acetone was added portionwise to the reaction mixture with continuous stirring. The white precipitate of dicyclohexylurea was formed after $10-15 \mathrm{~min}$. The reaction mixture was stirred at room temperature and after the disappearance of BTAA (TLC control), it was filtered. The filtrate was evaporated to dryness. The residue was taken up with cooled acetone and then filtered. The acetone filtrate was precipitated in diethylether at $10^{\circ} \mathrm{C}$. The products prepared were purified by repeated precipitation in ether. Typical spectral data (Example, Jeff ${ }_{2000}(\mathrm{BT})$ ): IR $\left(\mathrm{CHCl}_{3}, \mathrm{~cm}^{-1}\right): 3300,3500\left(v_{\mathrm{NH}}\right.$, amide $), 1675\left(v_{\mathrm{CO}}, \mathrm{BT}\right.$ and amide), $1100\left(v^{\text {as }}, \mathrm{CH}_{2} \mathrm{OCH}_{2}\right) .{ }^{1} \mathrm{H}$ NMR (DMSO$\left.d_{6}\right), \delta: 1.00-1.08\left(\mathrm{~m}, \mathrm{CH}_{3}\right), 3.24-3.58$ (broad $\mathrm{m}$, $\left.\left.\mathrm{CH}_{3} \mathrm{CH}(\mathrm{NH})\right), \quad\left[\mathrm{OCH}_{2} \mathrm{CH}_{2}\right]_{n}\right), 4.56(\mathrm{~d}, J=2.11 \mathrm{~Hz}$, $\left.\mathrm{N}-\mathrm{CH}_{2}\right), 7.10-7.66(\mathrm{~m}$, arom. $\mathrm{H}), 8.18$ and $8.24(\mathrm{~d}, \mathrm{~d}$, $J=8.08 \mathrm{~Hz}, \mathrm{NH})$.

\section{RESULTS AND DISCUSSION}

Acylation of the amino-end groups of Jeffamines ${ }^{\circledR}$ (MW from $230 \mathrm{Da}$ to $2000 \mathrm{Da}$ ) was carried out by means of BOAA or BTAA. The modification of the Jeffamines was confirmed by the appearance of intensive UV absorbance of the derivatives. The degree of $\mathrm{N}$-acylation was determined from the UV spectra. The modified polyethers containing benzoxazolon-3-yl-acetamido endgroups (Jeff-BO), were synthesized using the chloride of BOAA in $\mathrm{CH}_{2} \mathrm{Cl}_{2}\left(0-5^{\circ} \mathrm{C}\right)$ in the presence of $\mathrm{Et}_{3} \mathrm{~N}$ (Scheme 1, route i). ${ }^{11} \mathrm{~A}$ degree of $\mathrm{N}$-acylation in the range from 70 to $85 \%$ was achieved. The modified polyethers, containing benzothiazolon-3-yl-acetamido
Table I. Molecular weight characteristics (SEC), yield and degree of $\mathrm{N}$-acylation of Jeffamine derivatives

\begin{tabular}{|c|c|c|c|c|c|}
\hline $\begin{array}{c}\text { Product } \\
\text { No. }^{\mathrm{a}}\end{array}$ & $\bar{M}_{w}$ & $\bar{M}_{n}$ & $\bar{M}_{w} / \bar{M}_{n}$ & $\frac{\text { Yield }}{\%}$ & $\begin{array}{c}\text { Degree of } \\
N \text {-acylation/ } \\
\% \mathbf{b}\end{array}$ \\
\hline Jeff $_{230} \mathrm{BO}$ & 620 & 580 & 1.07 & 58 & 70 \\
\hline Jeff $_{400} \mathrm{BO}$ & 780 & 710 & 1.10 & 60 & 58 \\
\hline Jeff $_{600} \mathrm{BO}$ & 1070 & 1010 & 1.07 & 69 & 75 \\
\hline Jeff $_{900} \mathrm{BO}$ & 1240 & 1150 & 1.08 & 78 & 50 \\
\hline Jeff $_{2000} \mathrm{BO}$ & 2480 & 2250 & 1.10 & 88 & 85 \\
\hline $\mathrm{Jeff}_{400} \mathrm{BT}$ & 800 & 750 & 1.07 & 75 & 83 \\
\hline Jeff $_{600}$ BT & 1020 & 950 & 1.07 & 90 & 89 \\
\hline Jeff $_{900}$ BT & 1300 & 1200 & 1.08 & 89 & 86 \\
\hline Jeff $_{2000}$ BT & 2530 & 2300 & 1.10 & 91 & 94 \\
\hline
\end{tabular}

a Data for starting Jeffamines: $\bar{M}_{n}$ (VPO): JeffD ${ }_{230}-255$, JeffD ${ }_{400^{-}}$ 428, JeffED ${ }_{600}-600$, JeffED ${ }_{900}-927$, JeffED $E_{2001}-1900 ; \bar{M}_{w}$-not determined. ${ }^{b}$ Based on UV spectral data.

end-groups (Jeff-BT) were obtained in the presence of DCC in acetone at $23^{\circ} \mathrm{C}$ (Scheme 1 , route ii). ${ }^{2,3,12}$ By applying this method Jeff-BT, a degree of substitution of $83-94 \%$ was attained (Table I).

Jeff-BO and Jeff-BT are highly viscous oils $\left(23^{\circ} \mathrm{C}\right)$. All of them are soluble in chlorinated hydrocarbons, methanol, ethanol, acetone, tetrahydrofuran, and dimethylsulfoxide. Jeff-BO and Jeff-BT based on polyoxyethylenes (from Jeffamines ED precursors, MW 600-2000) are soluble in water, Jeff-BO and Jeff-BT based on polyoxypropylenes (from Jeffamines D precursors, MW 230 and 400) are sparingly soluble in water. Evidently, the more hydrophilic polyoxyethylene chain favors the water solubility of the prepared derivatives.

The molecular weight characteristics of the obtained diamides are summarized in Table I. The synthesized BOAA (BTAA)-conjugates are homogeneous by SEC. The analyses showed that Jeff-BO and Jeff-BT do not contain unreacted (2-benzoxa(thia)zolon-3-yl)acetic acid. The relatively narrow molecular weight distribution $\bar{M}_{w} / \bar{M}_{n}=1.07-1.10$ was retained in the process of chemical modification.

The amide bond formed was proved by IR and ${ }^{1} \mathrm{H}$ NMR spectral data. Amide bands $\left(1675 \mathrm{~cm}^{-1}\right)$ as well as a band characteristic of the valence vibration of the $\mathrm{NH}$ group of the amide bond $\left(3300-3500 \mathrm{~cm}^{-1}\right)$ are clearly seen in the IR spectra of all compounds studied. The formation of an amide bond between BOAA (BTAA) and corresponding Jeffamine was proved by the appearance of two doublet signals at $\delta$ in the range of $8.20-8.26 \mathrm{ppm}$ in the ${ }^{1} \mathrm{H}$ NMR spectra ( $\mathrm{NH}$ of the amide bond, $J=8 \mathrm{~Hz}$ ).

In conclusion, the high $N$-acylation degree achieved in the synthesis of Jeff-BT shows that the DCC method remains one of the most efficient methods of acylation of $\alpha, \omega$-diaminopolyethers.

\section{REFERENCES AND NOTES}

1. M. I. Stil'man, Itogi nauki i techn., Khim. I techn. Vysokomolek. Soedin., 20, 252 (1985).

2. S. Zalipsky, C. Gilon, and A. Zilkha, Eur. Polym. J., 19, 1177 (1983).

3. S. Zalipsky, C. Gilon, and A. Zilkha, J. Macromol. Sci., Chem., 21, 839 (1984).

4. C. K. Cain and A. P. Poszkowski, "Psychopharmacological 
Agents," Vol. 1, M. Gorden, Ed, Academic, New York, N.Y., 1964, p 329.

5. A. Lespagnol, Ch. Lespagnol, D. Lesieur, A. Marcincal-Lefebvre, and C. Dupont, Chem. Ther., 2, 347 (1967).

6. J. J. D'Amico and Braz. Pedido, PI 7806, 177 [Chem. Abstr., 92, 76490e (1980)].

7. C. Branca, C. A. Maggiali, M. R. Mingiardi, and D. Ricci, J. Plant Growth Regul., 1, 243 (1982).

8. Z. Mincheva, N. Stambolieva, and I. Rashkov, Eur. Polym. J.,
30, 761 (1994)

9. Z. Mincheva, N. Stambolieva, K. Petrova, and B. Galunsky, Biotechnol. Techn., 10, 727 (1996).

10. V. Kalcheva, Annuaire de L'Université de Sofia "Kliment Ochridsky"-Faculté de Chimie, 1967-1968, 62, 501 (1970) [Chem. Abstr., 73, 130917 (1970)].

11. V. Kalcheva, Z. Mincheva, and P. Andreeva, Arzneim.-Forsch., 40, 1030 (1990).

12. A. Hassner and V. Alexanian, Tetrahedron Lett., 46, 4475 (1978). 